\title{
Uyku Laboratuvarı'nda Kimler Uyuyor? Bir Retrospektif Çalışma
}

\section{Who are Sleeping in Sleep Laboratory? A Retrospective Study}

\author{
Mine Ayşe Altun Emirza, Aylin Bican, İbrahim Bora, Güven Özkaya* \\ Uludağ Üniversitesi Tip Fakültesi, Nöroloji Anabilim Dalı, Bursa, Türkiye \\ *Uludă̆ Üniversitesi Tip Fakültesi, Bioistatistik Anabilim Dalı, Bursa, Türkiye
}

\section{Özet}

Amaç: Bu çalışmada, uyku laboratuarımızdaki hasta verilerimiz derlenerek, hastaların başvuru şikayetleri, değerlendiren hekimin ön tanıları ile uyku bozukluklarının tanısında altın standart olan polisomnografi (PSG) tetkik sonuçlarının karşılaştırılması amaçlanmıştır.

Gereç ve Yöntem: Çalışmamıza PSG yapılan 656 hasta dahil edildi. Tüm olguların yaş, cinsiyet, eşlik eden kronik hastalık, başvuru şikayetleri, değerlendiren hekim tarafından düşünülen ön tanıları ve PSG tetkik sonucu tanıları retrospektif olarak değerlendirildi.

Bulgular: Çalışmamızda 656 hastanın \%43’ü kadın, \%57’si erkek ve yaş ortalaması 56 idi. Hastaların başvuru şikayetleri horlama, yorgunluk, uykuda nefes durması, uykusuzluk, baş ağrısı, gün içi uyku hali, bacaklarda huzursuzluk ve uykuda anormal davranışlardı. Ön tanılara göre PSG tetkiki sonrası tanıların; Obstruktif Uyku Apne Sendromu (OUAS), narkolepsi, REM Davranış Bozukluğu (RDB)'nda azaldığı ( $\mathrm{p}<0,05)$, basit horlama ve insomnide arttığı ( $\mathrm{p}<0,05)$, Huzursuz Bacak Sendromu (HBS) ve parasomnide uygun olduğu $(\mathrm{p}>0,05)$ bulunmuştur. Hastaların uyku sorunlarına kronik hastalık olarak hipertansiyon $(\% 34,3)$, diyabet $(\% 12,8)$, Kronik Obstruktif Akciğer Hastalığ1 (KOAH) (\%1,2), epilepsi (\%1,8), Parkinson hastalığ $(\% 3,5)$, demans (\%3,2), depresyon $(\% 18,4)$, kardiyovasküler hastalık $(\% 13,3)$ ve beyin damar hastalığ $(\% 4,9)$ eşlik etmekteydi.

Sonuç: Uyku polikliniğinde değerlendirilen hastaların ayırıcı tanılarının doğru yapılabilmesi, kesin teşhislerin zamanında konulabilmesi ve uygun tedavi modalitelerinin belirlenmesi için iyi anamnez ve fizik muayene ile birlikte PSG’nin doğru yorumlanmasını önermekteyiz. (Türk Nöroloji Dergisi 2012; 18:21-5)

Anahtar Kelimeler: Uyku bozuklukları, horlama, polisomnografi, kronik hastalık, ön tanı

\section{Summary}

Objective: Aim of this study is to compare the results of gold standard in diagnosing sleep disorders polysomnography (PSG) with the physician's preliminary diagnosis and complaints of patients in our data of sleep laboratory.

Material and Method: 656 patients who made PSG were included in the study. All of the patients' age, gender, comorbid chronic disease, complaints, preliminary diagnosis and PSG diagnosis were evaluated retrospectively.

Results: In our study, the average age of patients was 56 and $43 \%$ women $57 \%$ were male. Complaints of patients were snoring, fatigue, stopped breath during sleep, insomnia, headache, daytime sleepiness, restless legs and abnormal behaviors during sleep. According to preliminary diagnoses and PSG diagnoses; Obstructive Sleep Apnea Syndrome (OSAS), narcolepsy, REM behavior disorder (RBD) reduced ( $<<0.05$ ), simple snoring and insomnia increased ( $<0.05$ ), Restless Legs Syndrome (RLS) and parasomnia comply with ( $>>0.05$ ). Sleep disorders in patients were accompanied by chronic diseases, hypertension (34.3\%), diabetes (12.8\%), Chronic Obstructive Pulmonary Disease (COPD) (1.2\%), epilepsy (1,8\%), Parkinson's disease (3.5\%), dementia (3.2\%), depression $(18,4 \%)$, cardiovascular disease $(13.3 \%)$ and cerebrovascular disease (4.9\%).

Discussion: We are offering a good clinical history and physical examination with the correct interpretation of PSG for the differential diagnosis can be made true, accurate diagnoses and appropriate treatment modalities in our patients. (Turkish Journal of Neurology 2012; 18:21-5)

Key Words: Sleep disorders, snoring, polysomnography, chronic disease, pre-diagnosis

Yazışma Adresi/ Address for Correspondence: Dr. Mine Ayşe Altun Emirza, Uludağ Üniversitesi Tıp Fakültesi, Nöroloji Anabilim Dalı, Bursa, Türkiye Tel.: +90 2242951740 E-posta: mineliza@gmail.com

Geliş Tarihi/Received: 12.08.2011 Kabul Tarihi/Accepted: 14.10.2011 


\section{Giriş}

Uyku, organizmanın çevreyle iletişiminin değişik şiddette uyaranlarla geri döndürülebilir biçimde geçici, kısmi ve periyodik olarak kaybolması sürecidir. Bu süreç vücudun dinlenmesi, hücrelerin tamiri, yenilenmesi, hafiza fonksiyonlarının düzenlenerek öğrenmenin sağlanması ve yeni bir güne hazırlanma dönemidir. Uykunun normal yaşanması sağlıklı hayatın vazgeçilmez bir unsurudur. Uyku sırasında sağlıklı bireylerde solunum ve dolaşım sistemi de dahil olmak üzere tüm sistemlerde değişiklikler oluşmaktadır (1).

Uykuyla ilgili bozuklukları değerlendirdiğimizde hastalar bize kendilerini uyku bozukluğu düşündüren semptomlar ve bunların bir arada bulunduğu klinik tablolarla sunarlar. Bu semptomlar, uykusuzluk, gündüz aşırı uykululuk hali ve gece içinde uyku ya da uyanıklıklar sırasında ortaya çıkan anormal hareketler veya davranışlar olarak tanımlanabilir. Hastalarımızı bize yönlendiren kendilerinin ve çevrelerinin gözlemlerine göre horlama, solunum problemleri, yorgunluk, uyku paralizileri, gün içi uyku hali, uyku başlangıcında bacaklarda sıklıkla görülen hoş olmayan duygular, hipnogojik veya hipnopompik halüsinasyonlar, katapleksi gibi belirtiler gelebilmektedir ki tanıda önemli ipuçları sağlamaları açısından mutlaka sorgulanmalıdır (2). Bunların dışında toplumda sıkça görülen bir belirti olan baş ağrısı bir uyku bozukluğu sonucu da ortaya çıkabilir.

Uyku hastalıkları ile ilgili ilk sınıflama 1979 yılında yapılmıştır (3). Uyku tıbbındaki hızlı gelişme ve bilgi birikimi nedeniyle kısa sürede bu sınıflama güncelliğini kaybetmiştir. Amerikan Academy of Sleep Medicine (AASM) tarafindan biraz daha geliştirilerek International Classification of Sleep Disorders1 (ICSD-1) adıyla 1991 yılında yayınlanmıştır. Sınıflama 1997 ve 2001 yıllarında küçük revizyonlar geçirmiştir. AASM'nin 2005 yılında yeniden düzenlediği sınıflamaya göre uyku bozuklukları (ICSD-2) 8 ana başlıkta incelenmektedir (4). Bu başliklar;

1- Uykusuzluklar (İnsomni): Uykuya dalma, uykuyu sürdürmede yetersizlik, dinlendirici olmayan uyku, erken uyanma ve tekrar uyuyamama, sık uyanma olarak tanımlanır. İnsomni genellikle yaş, cinsiyet, eğitim düzeyi ve karakter özellikleri ile ilgili olup, sosyo-ekonomik konumun düşük olması, psikiyatrik veya kronik sistemik hastalıklarda daha sıklıkla görülebilmektedir. Mükemmeliyetçi, obsesif, gergin yapıda kişilerde de uykusuzluk daha yaygındır (5). İnsomninin erişkin nüfustaki sıklığ $1 \% 30-40$ civarında olup, ağır ve kalıcı bir şekilde uykusuzluktan yakınmaların oranı ise \%10-20' dir. ICSD-2, nedenlerine göre 11 alt tipe ayırır.

2- Uyku ile İlişkili Solunum Bozuklukları: Şiddetine göre sırasıyla intermitant horlama, primer horlama, üst solunum yolu direnç sendromu, Obstruktif Uyku Apne Sendromu (OUAS) ve obezite hipoventilasyon sendromunu kapsar. OUAS uyku sırasında tekrarlayan üst solunum yolu obstrüksiyonu dönemleri ve sıklıkla arteriyel oksijen satürasyonunda azalma ile karakterize bir sendromdur.
3- Santral Kökenli Hipersomniler: Narkolepsi, idiopatik hipersomni ve tekrarlayan hipersomniler büyük bir çoğunluğunu oluşturur.

4- Sirkadyen Ritim Bozuklukları: Kişinin fizik ve sosyal koşullarına uygun olan uyku-uyanıklık zamanlamasının bozulduğu klinik durumlardır.

5- Parasomniler: Uykuya girerken uykunun içinde veya uykudan uyanmalar sırasında ortaya çıkan, istenmeyen fiziksel olaylardır. Fizyolojik olarak REM uykusunda kas tonusu kaybolur. REM uykusuyla ilişkili bir parasomni olan REM Davranı̧̧ Bozukluğu'nda (RDB) ise kas tonusu kaybolmaz; hatta artı̧̧ gösterir ve bunun sonucunda hasta rüyalarını oynamaya başlar. Olguların çoğu ileri yaş grubundadır ve nedeni idiyopatiktir. Ancak son zamanlarda RDB ile Parkinson Hastalığ 1 , Multisistem Atrofiler ve Lewy Cisimcikli Demans gibi nörodejeneratif hastalıklar başta olmak üzere, birçok nörolojik hastalık arasında bir ilişki olduğu bulunmuştur (6).

6- Uyku ile İlişkili Hareket Bozuklukları: Huzursuz Bacak Sendromu (HBS), Periyodik Bacak Hareket Bozuklukları (PBHB) bu gruptadır. HBS, akşam saatlerinde ve özellikle yatağa yattıktan sonra bacaklarda ortaya çıkan, ağrı veya rahatsız edici bacak semptomları ile karakterize, dinlenme ile tetiklenen, hareketle geçen bir durumdur. HBS prevalansı çeşitli araştırmalarda \%5-10 arasında bildirilmiştir. HBS çok önemli bir uykusuzluk nedeni olup gece uyumakta zorlanan hastalar ertesi gün yorgunluk ve gün içi uyku halinden de yakınmaktadırlar (7). Bu durum günlük işlevlerde bozulmaya yol açabiliyor ve günlük semptomlar durum kronikleştikçe artabilmektedir.

\section{7- Tek Belirtiler, Normalin Değişik Şekilleri}

\section{8- Diğer Uyku Bozuklukları}

Çalışmamızda uyku bozukluğu nedeniyle polikliniğimize başvuran hastaların uyku semptomları, hekimin ilk aşamada düşündüğü ön tanıları, polisomnografi (PSG) tetkiki sonrası konulan tanıları açısından hastalarımızı retrospektif olarak değerlendirmeyi planladık. Böylelikle hastaların daha yoğun olan şikayetlerinin ve hekimin değerlendirmesinin uyku bozukluklarının tanısında altın standart olan PSG tetkik sonuçlarıyla karşılaştırılması amaçlandı. Çalışmamız için Uludağ Üniversitesi Tip Fakültesi Etik Kurul Komitesi’nden onay alındı.

\section{Gereç ve Yöntem}

\section{Klinik Değerlendirme}

Çalışmaya Mart 2005-Temmuz 2011 tarihleri arasında Uludağ Üniversitesi Tıp Fakültesi (UÜTF) Nöroloji Anabilim Dalı. Uyku Laboratuarı'nda PSG tetkiki yapılmış 656 hasta dahil edildi. Tüm olguların yaş, cinsiyet, eşlik eden kronik hastalık, başvuru şikayetleri, değerlendiren hekim tarafından düşünülen ön tanıları, PSG tetkiki sonucu tanıları ve PSG tetkiki verileri retrospektif olarak kayıt edildi.

\section{Uyku Polikliniği}

UÜTF Nöroloji Anabilim Dalı uyku polikliniği haftada 2 gün olmak üzere, ayda ortalama 50 hastaya randevu ile 
bakmaktadır. Hekim tarafından değerlendirilen hastanın uyku dosyası hazırlanmakta ve uyku bozukluğu ön tanısı düşünülen hastalara PSG tetkiki için randevu verilmektedir. Hastalarımıza randevu tarihinde PSG tetkiki ve narkolepsi düşünülen hastalar için ertesi gün Çoklu Uyku Latansı Testi (ÇULT) yapılmaktadır. Çalışmamızda PSG tetkiki yapılmış hastaların dosyaları retrospektif olarak tarand 1 ve veriler değerlendirmeye alındı.

\section{PSG (Polisomnografi) Tetkiki}

Hastaların PSG tetkiki öncesinde kafeinli gıda ve alkol almamaları önerildi (8). Bu esnada vücut kitle indeksi ve boyun çapı ölçümleri yapıldı. Tüm gece çekimi Grass Telefactor (AS 40 Amplifier system) cihazı ile çekildi. Standart PSG tetkikinde dört kanal elektroansefalografi (EEG) (C3/A2; C4/A1; O1/A2; O2/A1), iki kanal elektrookulogram (EOG), submental ve anterior tibial kas (her iki bacak için ayrı ayrı) elektromyogram (EMG) ve elektrokardiyogram (EKG) elektrotlar kullanıldı. Thermistor (oronazal airflow), pulse oksimetre, abdominal ve torasik vücut sensörleri de mevcuttu, oro-nazal kanül kullanılmadı. Hastaların görüntüleri infrared video kamera ile uyku teknisyeni tarafından izlendi ve kayıtları alındı. Hastalar gece saat 23.00' de yatırilip sabah saat 07.00' de uyandirıldı.

Uyku skorlaması 30 saniyelik epokların Rechtshaffen ve Kales standart kriterlerine göre yapıldı. Apne oronazal airflowda 10 saniye ya da daha fazla süren solunum durmas1, hipopne ise hava akımında ya \%50 azalma ya da \%50' den daha az bir azalma ile birlikte $\mathrm{SaO} 2$ ' de en az \%3'lük azalma veya arousal olması olarak değerlendirildi. Hastalara Uluslararası Uyku Bozuklukları sınıflaması kriterlerine göre OUAS tanısı konuldu. Apne Hipopne İndeksi (AHI) saatte 5 ve üzeri olan ve pulse oksimetre ile ölçülen oksijen satürasyonu \%90'ının altında seyretmesi göz önünde bulunduruldu. OUAS tanıları devam eden tüm hastalarımıza Sürekli Pozitif Havayolu Basınc1 (Continuous Positive Airway Pressure-CPAP) titrasyonu yapıldı. Parasomni ön tanıları olan ve epilepsi ile birlikte uyku bozukluğu düşündüğümüz hastalarımızın uyku kayıtlarında diğer standart çekim ile birlikte epilepsi protokolünde EEG çekimi (10-20 sistemine göre 21 elektrot yerleştirilerek) yapılmıştır.

ÇULT, uzun gece çekimi sabahında saat 09.00‘ da başlandı ve 20 dakika uyku olmak üzere 5 kez tekrarlandı. ÇULT çekimi sırasında hekim takibinde 30 saniyelik uyku epokları REM başlangıç uykusu (SOREM) dikkate alınarak skorlandı. Hastalara Uluslararası Uyku Bozuklukları sinıflaması kriterlerine göre narkolepsi tanısı konuldu. Diğer hastalar da değerlendirilip Uluslararası Uyku Bozuklukları sınıflaması kriterlerine göre tanıları konuldu (9).

Güniçi Uykululuk Değerlendirme

Hastaların gündüz uykululuğun değerlendirilmesinde Türkçe vaildasyonu yapılmış olan Epworth uykululuk skalası (Epworth sleep scale, ESS) kullanılmıştır. 10 puan üzeri yüksek (uykululuk) olarak kabul edilmiştir (10).

\section{İstatiksel Yöntem}

Çalışmanın istatistiksel analizi UÜTF Biyoistatistik Anabilim Dalı'nda, SPSS paket programı 16. sürüm kullanılarak yapıldı. Bağımsız grup karşılaştırmaları için t testi uygulandı. Gerekli görüldüğünde bu testlerin nonparametrik karşılıkları olan Mann Whitney U testi veya Wilcoxon testi kullanıldı. Sonuçlardan $\mathrm{p}<0,05$ olanlar istatistiksel olarak anlamlı kabul edildi.

\section{Bulgular}

Çalışmamızda 656 hastanın sonuçları sunulmuştur. \%43 kadın (282/656), \%57 (374/656) erkek idi. Yaş ortalaması 56 (18-77) olarak sonuçlandı. Tüm hastalara ESS yapıldı ve 11,0 (6-20) olarak sonuçlandı. Hastaların Uyku Laboratuarımızda ortalama uyku süreleri 7,1 saat/gece $(3,9-9,6)$ idi.

Uyku hastalarımızın polikliniğe çoğunlukla horlama ve uykusuzluk (uyku başlatma veya sürdürme zorluğu) yakınmalarıyla başvurduğunu gözlemledik. Hastalarının başvuru semptomları ve sıklıkları Tablo 1'de belirtilmiştir.

Hastalarımız poliklinikten basit horlama $\% 3$, OUAS $\% 43,3$, insomni $\% 13,3$, hipersomni $\% 12,5$, HBS $\% 6,7$, parasomni $\% 4$, narkolepsi \%6,4 ve RDB \%10,8 ön tanılarıyla yatırıldı.

Hastalarımıza CPAP/ BIPAP titrasyon geceleri de dahil olmak üzere (231 çekim) toplam 887 çekim yapıldı. PSG tetkiki sonrası tanıları basit horlama \%7,9 (52/656), OUAS \%24,5 $(161 / 656)$, santral apne ve OUAS \%3,5 (23/656), insomni $\% 17,9$ (116/656), HBS \%9,8 (64/656), HBS/PBHB \%6,7 (43/656), parasomni \%7,8 (51/656), artmıs derin uyku \%1,7 (11/656), Narkolepsi-Katapleksi Sendromu \%2 (12/656), RDB $\% 4,6$ (30/656), OUAS ve RDB \%0,5 (3/656), OUAS ve HBS/PBHB \%6,4 (42/656), normal uyku \%5,8 (38/656) idi (Tablo 2). CPAP titrasyonu başarılı olan $\% 31,7$ (208/656), CPAP titrasyonu başarısız olan \%2,8 (19/656), BIPAP titrasyonu \%0,6 (4/656) olarak sonuçland. HBS ve parasomni ön tanıları ile PSG sonrası tanılarının uygun olduğu $(\mathrm{p}>0,05)$ diğer hastalıklardan OUAS, narkolepsi, RDB ön tanısına göre PSG sonrası tanılarının

Tablo 1. Uyku polikliniğine hastaların başvuru semptomları

\begin{tabular}{lc}
\hline Hastaların geliş semptomları & $\%$ \\
\hline Horlama & 15,4 \\
Uykusuzluk & 14,2 \\
Gün içi uyku hali & 13,5 \\
Uykuda nefes durması & 11,4 \\
Uykuda nefes durması, horlama, gün içi uyku hali & 9,5 \\
Uykusuzluk, bacaklarda huzursuzluk & 7,9 \\
Horlama, baş ağrısı ve gün içi yorgunluk & 5,2 \\
Uykuda anormal davranışlar & 5,6 \\
Bacaklarda huzursuzluk, sürekli hareket ettirme isteği & 5 \\
Uykuda nefes durması, uykuya dalamama, gün içi uyku hali & 4,7 \\
Yorgunluk & 4,4 \\
Horlama, uykuda konuşma ve hareket & 1,4
\end{tabular}


Tablo 2. Uyku hastalarını ön tanıları ve PSG tetkiki sonrası tanıları

\begin{tabular}{|c|c|c|c|c|c|}
\hline & $\begin{array}{c}\text { Hastaların poliklinikte } \\
\text { yatış ön tanıları }\end{array}$ & & $\begin{array}{c}\text { PSG tetkiki sonucu } \\
\text { tanıları }\end{array}$ & & P değeri \\
\hline $\begin{array}{l}\text { Uyku ile ilişkili } \\
\text { solunum bozuklukları }\end{array}$ & $\begin{array}{c}\text { OUAS } \\
\text { Basit Horlama }\end{array}$ & $\begin{array}{c}\% 43,3 \\
\% 3\end{array}$ & $\begin{array}{c}\text { OUAS } \\
\text { Basit Horlama }\end{array}$ & $\begin{array}{c}\% 24,5 \\
\% 7,9\end{array}$ & $\begin{array}{l}0,000(\mathrm{p}<0,05) \\
0,028(\mathrm{p}<0,05)\end{array}$ \\
\hline İnsomni & İnsomni & $\% 13,3$ & İnsomni & $\% 17,9$ & $0,040(\mathrm{p}<0,05)$ \\
\hline \multirow[t]{2}{*}{ Hipersomni } & Narkolepsi & $\% 6,4$ & Narkolepsi & $\% 2$ & $0,032(\mathrm{p}<0,05)$ \\
\hline & İdiyopatik hipersomni & $\% 12,5$ & & & \\
\hline Parasomni & Parasomni & $\% 4$ & Parasomni & $\% 7,8$ & $0,072(\mathrm{p}>0.05)$ \\
\hline \multirow[t]{2}{*}{ Uyku ile ilişkili hareket bozuklukları } & HBS & $\% 6,7$ & HBS & $\% 9,8$ & $0,072(\mathrm{p}>0,05)$ \\
\hline & $\mathrm{RDB}$ & $\% 10,8$ & $\mathrm{RDB}$ & $\% 4,6$ & $0,038(\mathrm{p}<0,05)$ \\
\hline \multirow[t]{6}{*}{ Birden fazla uyku bozukluğu olanlar } & & & Santral apne+OUAS & $\% 3,5$ & \\
\hline & & & $\mathrm{HBS}+\mathrm{PBHB}$ & $\% 6,7$ & \\
\hline & & & $\mathrm{OUAS}+\mathrm{RDB}$ & $\% 0,5$ & \\
\hline & & & $\mathrm{OUAS}+\mathrm{HBS} / \mathrm{PBHB}$ & $\% 6,4$ & \\
\hline & & & Artmış derin uyku & $\% 1,7$ & \\
\hline & & & Normal uyku & $\% 5,8$ & \\
\hline
\end{tabular}

OUAS: Obstruktif Uyku Apne Sendromu, HBS: Huzursuz Bacak Sendromu, RDB: REM Davranış Bozukluğu, PBHB: Periyodik Bacak Hareket Bozuklukları.

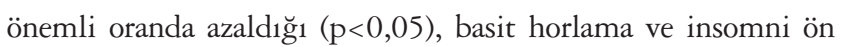
tanısına göre PSG sonrası tanılarının artmış oranda olduğu bulunmuştur $(\mathrm{p}<0,05)$ (Tablo 2).

Poliklinik değerlendirmemizde hastaların uyku sorunlarına, hipertansiyon \%34,3 (225/656), diyabet \%12,8 (84/656), Kronik Obstruktif Akciğer Hastalı̆̆1 (KOAH) \%1,2 (8/656), epilepsi \%1,8 (12/656), Parkinson \%3,5 (23/656), demans \%3,2 (21/656), depresyon (psikiyatri tarafindan takipte olan) \%18,4 (121/656), kardiyovasküler hastalık \%13,3 (87/656) ve beyin damar hastalığ1 \%4,9 (32/656) eşlik etmekteydi. Özellikle OUAS hastalarımıza hipertansiyon \%47,2 (109/231) ve kardiyovasküler hastalık \%17,8 (41/231), insomnili hastalarımıza depresyon \%48,3 (56/116), RDB olan hastalarımıza Parkinson Hastalığ $\breve{1}_{1} 48,5(16 / 33)$ ve demans \%42,4 (14/33), HBS/PBHB hastalarımıza diyabetin \%26 (40/153) oranlarında eşlik ettiğini gözlemledik.

\section{Tartışma}

Uyku bozuklukları toplumda sık görülmesine rağmen son zamanlarda daha ön planda olmaya başlamıştır. Toplumun giderek uyku bozukluklarının da bir hastalık olduğunu ve tedavi edilebileceği konusunda bilinçlenmesi ve hekimlerin de hastaları uyku sorunları açısından daha ayrıntılı ve dikkatli sorgulamaları sonucunda bu konudaki bilgi birikimimiz ve tecrübemiz giderek artmaktadir.

Polikliniğe uyku bozukluğu düşündüren semptomlarla başvuran hastalarımız için, hekim tarafından yapılan değerlendirmeler sonucunda, bir ön tanı oluşmaktadır ve bu ön tanılara göre PSG tetkiki yapılmasına karar verilmektedir. Hekimler tarafından değerlendirilen hastalarımız basit horlama
(\%3), OUAS $(\% 43,3)$, insomni $(\% 13,3)$, idiopatik hipersomni $(\% 12,5)$, HBS $(\% 6,7)$, parasomni $(\% 4)$, narkolepsi $(\% 6,4)$ ve RDB $(\% 10,8)$ ön tanılarıla yatırıldı. HBS ve parasomni ön tanıları ile PSG sonrası tanılarının uygun olduğu $(\mathrm{p}>0,05)$ diğer hastalıklardan OUAS, narkolepsi, RDB ön tanısına göre PSG sonrası tanılarının önemli oranda azaldığ $1(\mathrm{p}<0,05)$, basit horlama ve insomni ön tanısına göre PSG sonrası tanılarının artmış oranda olduğu bulunmuştur $(\mathrm{p}<0,05)$. Bu sonuçlar bize hastaların semptomlarının önceliği ile bizim sorgulamalarımız sonucu elde ettiğimiz ön tanı, uyku bozukluklarında altın standart olan PSG tetkiki sonucu olan tanılarının birlikte değerlendirilmesinin bir bütün olarak hastaya yaklaşımımızda önemli olduğunu göstermektedir.

Polikliniğe başvuru şikayetleri genel olarak horlama, uykuda nefes durması, gün içi uyku hali, baş ağrısı, yorgunluk ve uykusuzluktur. Bunlardan OUAS'larda horlama, gün içi uyku hali ve uykuda nefes durması gibi semptomlar, insomnilerde uykusuzluk ve uykuya dalamama gibi semptomlar, narkolepside yorgunluk, gün içi uyku hali olmaktadır. Bu semptomlardan bir kısmı ön tanıyı, gerçek tanıdan saptırabilmektedir. Örneğin uykusuzluk şikayeti ile başvuran hastalara HBS'ye yönelik sorgulama yapılmadığında, PSG tetkiki sonucunda insomni ön tanısı olan hastaların yüksek oranda HBS/PBHB tanılarını aldı bulunmuştur. $\mathrm{Bu}$ sonuçla polikliniğe uykusuzlukla gelen ve insomni ön tanısı olan hastalarımızı HBS açısından daha detaylı sorgulamamız gerektiğini fark ettik. Yine OUAS hastalarımızın en sık horlama ve uykuda nefes durması şikayetleri ile başvurduklarını, bunların \%6'sının da sabah baş ağrıları olduğunu tespit ettik.

Ayrıca uyku bozukluklarındaki kronik hastalık birlikteliği dikkat çekicidir, bu da öntanıyı etkileyebilir. Uyku bozukluklarıyla ilişkisi bilinen kronik hastalıkların başında 
KOAH, diabetes mellitus, kronik böbrek hastalığ ${ }_{1}$, kronik ağr1, Parkinson hastalığ 1 , demans, depresyon ve kanser gelmektedir (11). Çalışmamızda OUAS hastalarımıza hipertansiyon $(\% 47,2)$ ve kardiyovasküler hastalık $(\% 17,8)$, insomnili hastalarımıza depresyon (\%48,3), RDB olan hastalarımıza Parkinson Hastalı̆̆ 1 $(\% 48,5)$ ve demans $(\% 42,4), \mathrm{HBS} / \mathrm{PBHB}$ hastalarımıza diyabetin (\%26) eşlik ettiğini gözlemledik. Bu nedenle uyku bozukluğu düşündüren semptomlarla başvuran hastalar değerlendirilirken özgeçmişlerinin sorgulanması, bize tanı hakkında ipuçları verebilmektedir.

Araştırma süresinde kullandığımız tüm veriler hastaların dosyalarının incelenmesiyle elde edilmiştir. Çalışmamızdaki en sıkıntılı kısıtlılık klinik görüşmeler sırasında doldurulan formların zaman zaman eksiklik içermesiydi. Sağlıklı kayıtlamalar ile daha güvenilir retrospektif araştırmaların yapılabilmesini sağlayacaktır. Türkiye'de uyku tıbbı ile ilgili yapılan araştırmalar önemli bir deneyim birikimini yansıtmakta, bu sonuçlarla uyku bozuklukları hakkında hekimlerimizin ve toplumun bilgilenmesi, bilinçlenmesi ile birlikte uyku tıbbının ülkemizdeki gelişimine katkı sağlayacaktır.

Sonuç olarak analizini yaptığımız 6 yıllık süre içerisinde uyku polikliniğimizin sonuçlarını paylaştık. Uyku polikliniğinde değerlendirilen hastaların ayırıcı tanılarının doğru yapılabilmesi, kesin teşhislerin zamanında konulabilmesi ve uygun tedavi modalitelerinin belirlenmesi için iyi anamnez, fizik muayene ile birlikte PSG tetkikinin doğru yorumlanmasını önermekteyiz.

\section{Kaynaklar}

1. Kaynak H, Kaynak D. Uykuda solunum bozuklukları. T Clin J Psychiatry 2001;2:103-7.

2. Atay T. Uyku Bozukluklarının Temel Belirtileri. In: Kaynak H, Ardıç S (eds) Uyku Fizyolojisi ve Hastalıkları. Ankara: Nobel tıp kitapevi, 2010:16;111-117.

3. ASDA-Dagnostic Classification Steering Commitee. The İnternational classification of sleep disorsers. Diagnostic and coding manual, 2nd ed. Lawrance, KS: Allen Pres Inc; 1997.

4. International classification of sleep disorders, version 2: Diagnostic coding manuel. American Acedemy of sleep medicine, Rochester MN, 2005.

5. Schmutte T, Harris S, Levin R, Zweig R, Katz M, Lipton R. The relation between cognitive functioning and self-reported sleep complaints in nondemented older adults: results from the Bronx aging study. Behav Sleep Med 2007;5:39-56.

6. Stores, G. Clinical diagnosis and misdiagnosis of sleep disorders. J Neurol Neurosurgery Psychiatry 2007;78:1293-7.

7. Erman MK. Selected sleep disorders: restless legs syndrome and periodic limb movement disorder, sleep apnea syndrome, and narcolepsy. Psychiatr Clin North Am. 2006;29:947-67.

8. Aydın H, Sütçügil L. Uykuda bilişsel işlevler. Türkiye Klinikleri Psikiyatri, Uyku ve Bozuklukları Özel sayısı 2001;2:75-8.

9. Kryger MH, Roth T, Dement WC. Principles and Practise of Sleep Medicine. 3rd ed. Philadelphia: WB Saunders, 2000.

10. Johns MW. A new method for measuring daytime sleepiness: the Epworth sleepiness scale. Sleep 1991;14:540-5.

11. Ancoli-Israel S. The impact and prevalence of chronic insomnia and other sleep disturbances associated with chronic illness. Am J Manag Care 2006;12(8 Suppl):221-9. 